\title{
Risk factors for multidrug-resistant tuberculosis among tuberculosis patients: a case-control study
}

\section{Abdulhalik Workicho Wondwosen Kassahun Fessahaye Alemseged}

Department of Epidemiology, College of Health Sciences, Jimma University, Jimma, Ethiopia
Correspondence: Abdulhalik Workicho Department of Epidemiology, College of Health Sciences, Jimma University, PO Box 378, Jimma, Ethiopia Tel +25I 9| 3407305

Email abdulhalikw@gmail.com
This article was published in the following Dove Press journal:

Infection and Drug Resistance

13 March 2017

Number of times this article has been viewed

Background: Multidrug-resistant tuberculosis (MDR-TB) did not receive major attention until recently in sub-Saharan Africa where the tuberculosis incidence and risk factors are highest. Factors leading to development of drug resistance need to be understood to develop appropriate control strategies for national programs. The objective of this study was to identify the risk factors for MDR-TB among tuberculosis patients.

Methods: A case-control study was conducted to assess sociodemographic, behavioral and clinical risk factors using a structured questionnaire and clinical record reviewing. The data were entered and analyzed using SPSS windows version 16. Descriptive analysis was done to generate summary values for the variables and those significant variables in the bivariate analysis at $p$-value less than 0.25 were entered to multivariable logistic regression to identify independent determinants. Statistical significance was declared at $p$-value less than or equal to 0.05 .

Results: A total of 90 cases and 90 controls were included in the study. Age of respondents (adjusted odds ratio $[\mathrm{AOR}]=7 ; 95 \%$ confidence interval [CI]: 2.6-24.5), living in a household with only one room $(\mathrm{AOR}=5 ; 95 \% \mathrm{CI}$ : $1.68-15.38)$, history of previous treatment $(\mathrm{AOR}=21$; 95\% CI: 17.8-28) and being HIV infected (AOR=3.1; 95\%CI: 1.02-9.4) were found to be independent predictors of MDR-TB.

Conclusion: In light of these findings, the strategies in controlling MDR-TB should emphasize on patients with HIV coinfection, young patients, those who have a history of previous treatment, and those living in crowded places.

Keywords: MDR-TB, risk factors, case-control study, St. Peter's TB Specialized Hospital, Ethiopia

\section{Introduction}

Tuberculosis (TB) is one of the major public health problems that is most-frequently the cause of death among adults, despite being nearly $100 \%$ curable. It has also infected almost one-third of the world's population. Currently the global strategy to control TB is through preventing infection by efficient case finding and treatment and which helps to stop the infection from progressing to an active disease. ${ }^{1}$ One of the challenges in controlling TB is the presence of resistance. Multidrug-resistance tuberculosis (MDRTB) is defined as resistance to at least rifampicin and isoniazid. The bacteriological cause is the transmission of MDR-TB strains in new cases or the selection of single drug resistant strains induced by the previous treatment. It is an increasing global problem as most cases are occurring due to physician error and patient non-compliance during treatment. The extent of occurrence and its burden varies significantly from country to country and from region to region being high in resource poor countries., 
There were an estimated half a million cases of MDR-TB in 2007 with $5 \%$ of all TB cases having MDR-TB, just over $1 \%$ of the cases in 2008 were receiving treatment known to be based on World Health Organization (WHO) recommended standards. The countries that ranked first to fifth in terms of total numbers of MDR-TB cases in 2007 were India, China, the Russian Federation, South Africa, and Bangladesh. WHO reported that the highest rate of MDR-TB ever recorded, with peaks of up to $22 \%$ of new TB cases, was in some settings of the former Soviet Union. In the same region 1 in 10 cases of MDR-TB is extensively drug-resistant TB. ${ }^{2,3}$

Ethiopia ranks seventh among the world's 22 high-burden TB countries. The level of MDR-TB in Ethiopia among new TB cases is estimated at 2\%; 5,979 cases of MDR-TB were reported in 2007. ${ }^{4}$ More than 400,000 cases of MDR-TB emerge worldwide every year as a result of under-investment in basic activities to control TB, poor management of anti-TB drugs, and transmission of drug-resistant strains. MDR-TB is much more difficult and costly to treat than drug-susceptible TB. ${ }^{5}$ Recent surveys showed an MDR-TB prevalence of $26 \%$ among TB patients in Ethiopia (retreatment cases), 54\% in Nigeria (tertiary hospital patients), 9.5\% in Zambia (prisoners), and $9.4 \%$ in Rwanda (retreatment cases). On top of that, statistical modeling suggests that MDR rates in Africa could be much higher than originally anticipated. Overall, there appears to have been an alarming increase in the prevalence of MDR-TB in many areas of Africa, and better surveillance data are urgently needed. ${ }^{6-10}$

Attention to MDR-TB in sub-Saharan Africa has been neglected until recently, where TB incidence and risk factors are believed to occur in significant numbers. Though little is known about the risk factors in this region, as most of the studies were drug-resistant studies not risk factor studies, some of these risk factors were hypothesized to be male sex in young age group, presence of HIV infection, history of diabetes mellitus, history of known contact with TB, alcohol use, malnutrition, low socioeconomic status, and patients with a history of anti-TB treatment. ${ }^{11}$ For settings in low- and middle-income countries, WHO and its partners created "DOTS (directly observed treatment, short-course) Plus for MDRTB", a management strategy designed on the foundation and principles of DOTS. ${ }^{12}$ This research is believed to contribute to identifying the potential risk factors for MDR-TB, so that the management of patients will also be strengthened through preventing these factors, alongside patient treatment which will have a positive impact on successful treatment outcome, and decrease the burden of the disease as a whole.

\section{Methods}

\section{Ethics}

This specific study obtained ethical clearance from the Ethical Review Committee of Jimma University and St. Peter's TB Specialized Hospital, before data collection, written informed consent was obtained from the study participants.

\section{Study area and period}

A case-control study was conducted at St. Peter's TB Specialized Hospital, Addis Ababa, Ethiopia, the only place where treatment for MDR-TB was provided for patients from all over Ethiopia at the time of conducting this research (March to April, 2011). St Peter's TB Specialized Hospital is one of the Ministry of Health institutions in the capital, Addis Ababa with a mission to provide care for all referral TB cases in the country, HIV/AIDS patients, and in-patient care for both susceptible and resistant TB cases.

\section{Study population}

This study considered sampled cases and controls as study population. Cases were TB patients with culture positive Mycobacterium tuberculosis, resistant to at least isoniazid and rifampicin. Controls were sputum smear-positive TB patients who turned to sputum smear-negative after $2 \mathrm{nd}$, 5 th, or 7 th month of the treatment course.

\section{Sample size and sampling technique}

The sample size was calculated using Epi-Info 3.02 statistical software. HIV seropositivity was taken as the main research hypothesis variable and also a $40 \%$ prevalence of HIV/AIDS in TB patients, ${ }^{4}$ odds ratio of $2.55,{ }^{13}$ a $1: 1$ ratio between cases and controls, $80 \%$ power, and $95 \%$ confidence level were the other parameters used to calculate the sample size. Accordingly, the sample size with the addition of $10 \%$ for non-response was calculated to be 180 (90 cases and 90 controls). All cases and controls fulfilling the inclusion criteria were consecutively included in the study until the sample size was achieved.

\section{Data collection method and tool}

Interviews were conducted with the study participants using a pretested structured questionnaire and clinical records on the previous illness were reviewed by trained Health officers and Bachelor of Science Nurses. The questionnaire was first developed in English after reviewing literature, and translated to the language of the respondents (Amharic) then checked 
for its consistency through back-translation to English by qualified individuals who were also health professionals. The questionnaire encompasses variables to assess sociodemographic factors, environmental factors, and patient related factors. The data from cases were collected in the inpatient ward for admitted patients and during DOTS-plus practice for outpatients and data from controls were collected when the patients come to St. Peter's TB Specialized Hospital to collect their medication.

\section{Data analysis}

Data were entered and analyzed using Statistical Package for Social Sciences (SPSS) for Windows version 16. Descriptive statistical techniques were used to obtain summary values for cases and controls separately. Bivariate analysis was performed to identify the crude association between dependent and independent variables. The dependent variable was presence of MDR-TB and the independent variables include different sociodemographic, environmental and patient's health and behavior related variables. Statistical significance was determined using $p<0.05$ as a cut-off point and odds ratio was used to see the strength of association. Those variables which showed significant association in bivariate analysis were entered in a backward stepwise logistic regression procedure for multivariable logistic analyses, in order to assess the independent predictors of MDR-TB among the study participants.

\section{Results}

\section{Sociodemographic characteristics}

A total of 180 respondents, 90 cases and 90 controls, participated in the study. The mean age for cases was 29.3 (standard deviation [SD] 11.1) years, and 36.8 (SD 13.99) years for control group, and the majority (104 [57.8\%]) were within the age group of $\leq 30$ years. Males constituted $41(45.6 \%)$ of the cases and 52 (57.8\%) of controls. In cases and controls, Orthodox Christian $n=129$ (71.6\%), literate $n=147$ (81.6\%), and currently not married respondents $n=105$ (58.3\%) dominated the study groups (Table 1). Twenty-three $(25.5 \%)$ of cases and seven (8\%) control participants were students; $15(16.6 \%)$ of cases and $13(14.4 \%)$ of controls were house wives; 16 (17.7\%) of cases and $13(14.4 \%)$ of controls were government employees; 10 (11.1\%) of cases and 23 (25.5\%) of controls were daily laborers, followed by merchants and farmers by occupation. The majority of study participants, $n=37(44 \%)$ of cases and $n=44(59.5 \%)$ of controls, had an estimated monthly income of less than 500 Ethiopian Birr
Table I Bivariate analysis of the socio demographic characteristic of study participants with MDR-TB, at St. Peter's TB Specialized Hospital, April 20II

\begin{tabular}{|c|c|c|c|}
\hline Variables & $\begin{array}{l}\text { Case } N=90 \\
(\%)\end{array}$ & $\begin{array}{l}\text { Control } \\
\mathrm{N}=90 \text { (\%) }\end{array}$ & COR $(95 \% \mathrm{Cl})$ \\
\hline \multicolumn{4}{|l|}{ Age (years) } \\
\hline$\leq 30$ & $66(73.3)$ & $38(42.2)$ & $3.76(2.01-7.04)^{*}$ \\
\hline$>30$ & $24(26.7)$ & $52(57.8)$ & 1.00 \\
\hline \multicolumn{4}{|l|}{ Sex } \\
\hline Male & $4 I(45.6)$ & $52(57.8)$ & $0.6 \mathrm{I}(0.34-\mathrm{I} .10)$ \\
\hline Female & $49(54.4)$ & $38(42.2)$ & 1.00 \\
\hline \multicolumn{4}{|l|}{ Marital status } \\
\hline Currently married & $28(31.1)$ & $47(52.2)$ & 1.00 \\
\hline Others & $62(68.9)$ & $43(47.8)$ & $2.42(1.32-4.45)^{*}$ \\
\hline \multicolumn{4}{|l|}{ Educational status } \\
\hline Illiterate & II (I2.2) & $22(24.4)$ & $0.43(0.19-1.95)$ \\
\hline Literate & $79(87.8)$ & $68(75.6)$ & 1.00 \\
\hline \multicolumn{4}{|l|}{ Occupation } \\
\hline Employed for cash & $16(17.8)$ & $13(14.4)$ & $1.28(0.58-2.84)$ \\
\hline Not employed & 74 (82.2) & $77(85.6)$ & 1.00 \\
\hline \multicolumn{4}{|l|}{ Religion } \\
\hline Muslim & $8(8.9)$ & $21(23.3)$ & 1.00 \\
\hline Orthodox Christian & $64(71.1)$ & $65(72.2)$ & $2.6(1.07-6.30)^{*}$ \\
\hline Protestant & $18(20)$ & $4(4.4)$ & $12(3.04-45.80) *$ \\
\hline \multicolumn{4}{|l|}{ Monthly family } \\
\hline \multicolumn{4}{|l|}{ income (ETB) } \\
\hline$\leq 500$ & $37(44)$ & $44(59.5)$ & 1.00 \\
\hline $50 I-I, 000$ & $24(28.6)$ & $24(32.4)$ & $0.85(0.58-2.40)$ \\
\hline$>1,000$ & $23(27.4)$ & $6(8.1)$ & $4.5(1.67-12.38)^{*}$ \\
\hline
\end{tabular}

Notes: *Variables that showed significant association during bivariate analysis at $p<0.25$, COR.

Abbreviations: MDR-TB, multidrug-resistant tuberculosis; TB, tuberculosis; ETB, Ethiopian Birr; COR, crude odds ratio; $\mathrm{Cl}$, confidence interval.

(ETB) (Table 1). The bivariate analysis revealed that having previous TB treatment more than once, HIV infection, living in one room, and contracting diabetes were found to have a crude association with developing MDR-TB (Table 2).

\section{The overall predictors of developing MDR-TB}

All variables which had shown statistically significant association during the bivariate analysis, such as age of respondents, marital status, monthly family income, number of rooms in the household, history of previous treatment for TB, history of traditional treatment, patients having diabetes mellitus, and patients having HIV infection, were collectively entered in the multivariable analysis. In multivariable logistic regression analysis, four variables were found to be independent predictors for the occurrence of MDR-TB after controlling possible confounders. Those aged $\leq 30$ years were seven times more likely to have MDR-TB compared to respondents aged $>30$ years (adjusted odds ratio $[\mathrm{AOR}]=7,95 \%$ confidence interval 
Table 2 Bivariate analysis of environmental and patients' behavioral and health related factors with MDR-TB at St. Peter's TB Specialized Hospital, April 20II

\begin{tabular}{|c|c|c|c|}
\hline Variables & $\begin{array}{l}\text { Case } \\
\mathrm{N}=90 \text { (\%) }\end{array}$ & $\begin{array}{l}\text { Control } \\
\mathbf{N}=\mathbf{9 0}(\%)\end{array}$ & COR $(95 \% \mathrm{Cl})$ \\
\hline \multicolumn{4}{|c|}{ Have a house to live in } \\
\hline Yes & $74(82.2)$ & $77(85.6)$ & $0.78(0.35-1.73)$ \\
\hline No & $16(17.8)$ & $13(14.4)$ & 1.00 \\
\hline \multicolumn{4}{|c|}{$\begin{array}{l}\text { Number of rooms in } \\
\text { the house }\end{array}$} \\
\hline I & $50(6 I)$ & $35(43.2)$ & $2.05(1.01-3.83)^{*}$ \\
\hline$\geq 2$ & $32(39)$ & $46(56.8)$ & 1.00 \\
\hline \multicolumn{4}{|c|}{ Family size } \\
\hline$\leq 5$ & $57(69.5)$ & $60(75.9)$ & $0.72(0.36-1.45)$ \\
\hline$>5$ & $25(30.5)$ & $19(24.1)$ & 1.00 \\
\hline \multicolumn{4}{|c|}{ Have a TV } \\
\hline Yes & $55(67.1)$ & $42(51.9)$ & $1.89(1.00-3.56)^{*}$ \\
\hline No & $27(32.9)$ & $39(48.1)$ & 1.00 \\
\hline \multicolumn{4}{|c|}{ History of being } \\
\hline \multicolumn{4}{|l|}{ in prison } \\
\hline Yes & $9(10)$ & $14(15.6)$ & $0.603(0.25-1.48)$ \\
\hline No & $81(90)$ & $76(84.4)$ & 1.00 \\
\hline \multicolumn{4}{|c|}{$\begin{array}{l}\text { History of previous } \\
\text { treatment }\end{array}$} \\
\hline Yes & $82(91.1)$ & $30(33.3)$ & $20.5(8.80-47.60)^{*}$ \\
\hline No & $8(8.9)$ & $60(66.7)$ & 1.00 \\
\hline \multicolumn{4}{|c|}{ History of contact } \\
\hline Yes & $23(25.6)$ & $13(14.4)$ & $2(0.95-4.30)$ \\
\hline No & $67(74.4)$ & $77(85.6)$ & 1.00 \\
\hline \multicolumn{4}{|c|}{$\begin{array}{l}\text { Number of times of } \\
\text { previous } \mathbf{R x}\end{array}$} \\
\hline I time & $20(24.4)$ & $18(60)$ & 1.00 \\
\hline$\geq 2$ times & $62(75.6)$ & $12(40)$ & $4.65(1.90-11.29)^{*}$ \\
\hline \multicolumn{4}{|c|}{ History of defaulter } \\
\hline Yes & $15(16.7)$ & $10(11.1)$ & $1.6(0.67-3.78)$ \\
\hline No & $75(83.3)$ & $80(88.9)$ & 1.00 \\
\hline \multicolumn{4}{|c|}{$\begin{array}{l}\text { History of traditional } \\
\text { treatment }\end{array}$} \\
\hline Yes & $79(87.8)$ & $68(75.6)$ & $2.32(1.05-5.12)^{*}$ \\
\hline No & II (12.2) & $22(24.4)$ & 1.00 \\
\hline \multicolumn{4}{|c|}{ History of illicit } \\
\hline \multicolumn{4}{|c|}{ drug use } \\
\hline Yes & $4(4.4)$ & $8(8.9)$ & $0.47(0.14-1.64)$ \\
\hline No & $86(95.6)$ & $82(91.1)$ & 1.00 \\
\hline \multicolumn{4}{|c|}{ History of smoking } \\
\hline Yes & $13(14.4)$ & 17 (18.9) & $0.43(0.33-1.59)$ \\
\hline No & $77(85.6)$ & $73(81.1)$ & 1.00 \\
\hline \multicolumn{4}{|c|}{ Contract diabetes } \\
\hline \multicolumn{4}{|l|}{ mellitus } \\
\hline Yes & II (I2.2) & $\mathrm{I}(\mathrm{I} . \mathrm{I})$ & $12.4(1.56-98.10)^{*}$ \\
\hline No & $79(87.8)$ & $89(98.9)$ & 1.00 \\
\hline \multicolumn{4}{|c|}{ History of alcohol use } \\
\hline Yes & $17(18.9)$ & $25(27.8)$ & $0.61(0.30-1.22)$ \\
\hline No & $73(81.1)$ & $65(72.2)$ & 1.00 \\
\hline \multicolumn{4}{|c|}{ Presence of HIV } \\
\hline \multicolumn{4}{|l|}{ infection } \\
\hline Yes & $45(50)$ & $26(28.9)$ & $2.46(1.33-4.55)^{*}$ \\
\hline No & $45(50)$ & $64(7 \mathrm{I} .1)$ & 1.00 \\
\hline
\end{tabular}

Table 2 (Continued)

\begin{tabular}{|c|c|c|c|}
\hline Variables & $\begin{array}{l}\text { Case } \\
\mathrm{N}=90 \text { (\%) }\end{array}$ & $\begin{array}{l}\text { Control } \\
\mathrm{N}=90 \text { (\%) }\end{array}$ & COR $(95 \% \mathrm{Cl})$ \\
\hline \multicolumn{4}{|c|}{ History of mental illness } \\
\hline Yes & $10(11.1)$ & $5(5.6)$ & $2.13(0.69-6.48)$ \\
\hline No & 80 (88.9) & $85(94.4)$ & 1.00 \\
\hline
\end{tabular}

Table 3 Multiple logistic regression analysis of risk factors for MDR-TB among tuberculosis patients at St. Peter's TB Specialized Hospital, April 20II

\begin{tabular}{|c|c|c|c|}
\hline Variables & COR $(95 \% \mathrm{Cl})$ & AOR $(95 \% \mathrm{Cl})$ & $p$ \\
\hline \multicolumn{4}{|l|}{ Age } \\
\hline$\leq 30$ & $3.76(2.01-7.05)$ & $7(2.40-21.07)$ & 0.001 \\
\hline$>30$ & 1.00 & 1.00 & \\
\hline \multicolumn{4}{|c|}{ Number of rooms } \\
\hline \multicolumn{4}{|c|}{ in the house } \\
\hline I & $2.05(\mathrm{I} .0 \mathrm{I}-3.83)$ & $5.07(1.68-15.38)$ & 0.004 \\
\hline$\geq 2$ & 1.00 & 1.00 & \\
\hline \multicolumn{4}{|c|}{ History of previous Rx } \\
\hline Yes & $20.5(8.78-47.60)$ & $21(17.80-28.80)$ & 0.001 \\
\hline No & 1.00 & 1.00 & \\
\hline \multicolumn{4}{|c|}{ Infected with HIV } \\
\hline Yes & $2.46(1.33-4.55)$ & $3.1(1.02-9.40)$ & 0.046 \\
\hline No & 1.00 & 1.00 & \\
\hline
\end{tabular}

Abbreviations: $\mathrm{Rx}$, prescription; MDR-TB, multidrug-resistant tuberculosis; TB, tuberculosis; $\mathrm{COR}$, crude odds ratio; $\mathrm{AOR}$, adjusted odds ratio; $\mathrm{Cl}$, confidence interval.

[CI]: 2.4-21.07). Respondents who had previous history of treatment for TB were 21 times more likely to develop MDR-TB compared to those who had no previous history of TB treatment ( $\mathrm{AOR}=21 ; 95 \% \mathrm{CI}: 17.80-28.80)$. Those respondents living in a household with only one room were five times at higher risk of having MDR-TB than patients living in a household with two or more rooms $(\mathrm{AOR}=5.07$, 95\% CI:1.68-15.38). Finally, respondents who had HIV infection were three times more likely to have MDR-TB when compared to respondents who had no HIV infection $(\mathrm{AOR}=3.1,95 \%$ CI: 1.02-9.40) (Table 3).

\section{Discussion}

The study has provided pertinent information about factors associated with MDR-TB which can support activities being implemented to decrease the burden of TB in Ethiopia for planners and decision makers. Patients' age, history of previous treatment, and living in a house with only one room, were strong predictors for MDR-TB; while HIV infection had an association but of weaker statistical significance

Among the sociodemographic factors, only age of respondents and number of rooms in the household were 
significantly associated with the occurrence of MDR-TB. Study participants whose age was $\leq 30$ years were seven times more likely to have MDR-TB compared to those whose age was $>30$ years. This fact had been confirmed by different literature in different countries. ${ }^{14,15}$ According to a study which was conducted in one London TB hospital, patients with MDR-TB were found to be younger than patients who are drug-sensitive, and showed association of young age and MDR-TB (AOR $=1.83$; 95\% CI 1.02-1.05) and a national surveillance study in Switzerland indicated existence of an increased risk of resistance to any first line drug with being $<35$ years of age $(\mathrm{AOR}=1.5 ; 95 \% \mathrm{CI} 1.0-2.3)$. The resistance in young age could be due to reluctance in adhering to the medication in the specified age group. Unlike a cross-sectional study in Georgia, which identified female sex as risk factor for MDR-TB in the entire study population and female sex was independent risk factor among previously treated patients (AOR $=1.58,95 \%$ CI 1.02-2.32), the current study did not show association between sex and MDR-TB. The difference in the result may be explained by the difference in study design and different study population. ${ }^{14,15}$

Number of rooms in the household was found to be associated with MDR-TB in this study indicating that those patients living in a household with only one room were five times at higher risk of having MDR-TB than those living in a household with more than one room. This could be due to high risk of acquiring resistant strains from infected hosts in crowded places. The result also implied that awareness on the mode of transmission has to be provided for people living in a household with only one room whenever there are patients living together, by which we can decrease primary resistance which can occur through transmission of drug resistance strains.

In this study among patient's health problems and behavioral factors, previous history of TB treatment and HIV infection were significantly associated with developing MDR-TB. Patients who had previous history of treatment for TB had 21 times higher risk of developing MDR-TB than patients who did not have a history of previous treatment for TB. Even then though not as big, similar association has been found by a study in Georgia that revealed those with prior history of TB treatment to be more likely to develop MDR-TB than newly diagnosed patients $\left(\mathrm{AOR}=5.47\right.$; 95\%CI 3.87-7.74). ${ }^{14,16}$ The resistance could be due to repeated and inappropriate way of taking the medication that made the bacteria mutate and develop resistance against the drugs. In order to address this problem, effective implementation of the DOTS strategy and increasing number of institutions equipped with drug resistance tests for early detection of primary resistance is mandatory.

The current study revealed that study participants who had HIV infection were three times at higher risk than those who had no HIV infection to develop MDR-TB. This association has a marginal statistical significance showing that HIV infection is not a strong predictor of MDR-TB infection in TB patients. A finding with a stronger statistical association was identified by a study in the Netherlands which indicated that MDR-TB was significantly associated with HIV infection (AOR 3.43, $p=0.015$ ). ${ }^{17}$

A large survey $(n=13,344)$ conducted in the early 1990 s in France, representing $80 \%$ of French public hospital beds, observed an association between primary MDR-TB and HIV (AOR of 3.3; 95\% CI: 1.5-7.3), but not for acquired MDR-TB (AOR 1.0; 95\% CI 0.5-2.0). ${ }^{18}$ This finding could be explained by the fact that high prevalence of TB/HIV coinfection might lead the bacteria to resist the drugs. But on the contrary, most of the studies in different parts of Africa did not find association between HIV infection and MDR-TB. Three studies in South Africa found no association between HIV infection and MDR-TB. ${ }^{19,20}$ A South African study showed no differences in HIV prevalence between patients with drug-susceptible TB and those with drug resistance, although MDR-TB patients tended to have slightly higher rates of HIV infection $(60.0 \%$ vs $55.1 \%$; $p=0.575){ }^{19,20}$ Further research is therefore recommended to identify the relationship between HIV infection and drug resistance.

This study was conducted during a time where much was not known about MDR-TB risk factors in Ethiopia and there were no treatment centers other than the study site. Therefore, the information can help understand the situation at that time. As there are more treatment centers and numbers of patients treated are larger now, much wider, and follow up studies can be conducted to understand the full spectrum of the disease.

\section{Conclusion}

In conclusion, age of respondents, history of treatment for TB, living in a household with only one room, and HIV infection were found to be associated with developing MDR-TB. The TB control program should focus on improving patient's adherence to anti-TB drugs, further decreasing TB/HIV coinfection, and health promotion activities about TB should give special attention to the younger age group, and focus on means of transmission. A large-scale research to validate and produce out normative data for the general population of the country is recommended. 


\section{Acknowledgements}

This investigation received financial support from Jimma University. The authors appreciate the study participants for their cooperation in providing the necessary information. The staff at St Peter's TB Specialized Hospital and the data collectors are also acknowledged for their support during the study

\section{Author contributions}

AW conceived the study and was involved in the analysis, report writing, and drafting the manuscript. FA and WK were involved in the conception, design, and data analysis. All authors contributed toward data analysis, drafting and revising the paper and agree to be accountable for all aspects of the work.

\section{Disclosure}

The authors report no conflicts of interest in this work.

\section{References}

1. WHO. Global tuberculosis control. A short update to the 2009 report. 2009: Geneva.

2. Ethiopian Public Health Association. Quarterly Public Health Digest. 2010: Addis Ababa.

3. Ormerod LP. Multidrug-resistant tuberculosis (MDR-TB) epidemiology, prevention and treatment. Br Med Bull. 2005;73-74:17-24.

4. USAID. Ethiopia. Tuberculosis profile. 2006. Available from: http://pdf. usaid.gov/pdf_docs/Pdaci535.pdf. Accessed February 9, 2017.

5. WHO. The Global MDR-TB \& XDR-TB Response Plan 2007-2008. 2009: Geneva.

6. Meskel DW, Abate G, Lakew M, Goshu S, Aseffa A. Anti-tuberculosis drug resistance among retreatment patients seen at St. Peter's Tuberculosis Specialized Hospital. Ethiop Med J. 2008;46(3):219-225.
7. Kehinde AO, Obaseki FA, Ishola OC, Ibrahim KD. Multidrug resistance to Mycobacterium tuberculosis in a tertiary hospital. J Natl Med Assoc. 2007;99(10):1185-1189.

8. Umubyeyi AN, Vandebruel G, Gasana M, et al. Results of a national survey on drug resistance among pulmonary tuberculosis patients in Rwanda. Rwanda. Int J Tuberc Dis. 2007;11(2):189-194.

9. Nunn P, Zignol M, Jaramillo E, Wright A, Getahun H, TB drug resistance, is it really a threat to Africa? Ethiop Med J. 2007;45(4):399-404.

10. Cox H, M.C., Coetzee D, Prevalence of drug resistant tuberculosis and association with HIV in Khayelitsha, South Africa. 2009.

11. Diande S, Sangare L, Kouanda S, et al., Risk factors for multidrugresistant tuberculosis In four centers in Burkina Faso, West Africa. Microb Drug Resit. 2009;15(3):217-221.

12. LSHTM. A prioritized research agenda for DOTS-Plus for multidrugresistant tuberculosis (MDR-TB). 2003. Available from http://researchonline.1shtm.ac.uk/17595/. Accessed February 9, 2017.

13. Bruchfeld J, Aderaye G, Palme IB, et al, Molecular epidemiology and drug resistance of Mycobacterium tuberculosis isolates from Ethiopian pulmonary tuberculosis patients with and without human immunodeficiency virus infection. J Clin Microbiol. 2002;40(5):1636-1643.

14. National Collaborating Center for Chronic Conditions. Clinical diagnosis and management of tuberculosis and measures for its prevention and control. London: Royal College of Physicians. 2006.

15. Lomtadze N, Aspindzelashvili R, Janjgava M, et al. Prevalence and risk factors for multidrug-resistant tuberculosis in Republic of Georgia: a population based study. Int J Tuberc Lung Dis. 2009;13(1):68-73.

16. Balaji V, Daley P, Anand AA, et al. Risk factors for MDR and XDR-TB in a tertiary referral hospital in India. PLOS ONE. 2010; 5(3):e9527.

17. Haar CH, Cobelens FGJ, Kalisvaart NA, van der Have JJ, van Gerven JHJ, van Soolingen D. Tuberculosis drug resistance and HIV infection, the Netherlands. Emerging Infectious Diseases. 2007;13(5):776-778.

18. Robert J, Trystam D, Truffot-Pernot C, Carbonnelle B, Grosset J. Surveillance of Mycobacterium tuberculosis drug resistance in France, 1995-1997. Int J Tuberc Lung Dis. 2000;4(7):665-672.

19. Post FA, Wood R. HIV infection is not associated with an increased rate of drug-resistant tuberculosis. S Afr Med J. 1997;87(7):903.

20. Weyer, K, Brand J, Lancaster J, Levin J, M. Van der Walt M. Determinants of multidrug-resistant tuberculosis in South Africa: results from a national survey. S Afr Med J. 2007;97(11):1120-1128.
Infection and Drug Resistance

\section{Publish your work in this journal}

Infection and Drug Resistance is an international, peer-reviewed openaccess journal that focuses on the optimal treatment of infection (bacterial, fungal and viral) and the development and institution of preventive strategies to minimize the development and spread of resistance. The journal is specifically concerned with the epidemiology of antibiotic

\section{Dovepress}

resistance and the mechanisms of resistance development and diffusion in both hospitals and the community. The manuscript management system is completely online and includes a very quick and fair peerreview system, which is all easy to use. Visit http://www.dovepress.com/ testimonials.php to read real quotes from published authors. 